\title{
A Exploração dos rios Amazonas e Madeira no Império Brasileiro por Franz Keller-Leuzinger: imprensa e nação ${ }^{1}$
}

The Exploration of the Rivers Amazon and Madeira in the Brazilian Empire by Franz Keller-Leuzinger: the Press and Nation

\section{Moema de Rezende Vergara \\ Pesquisadora do Museu de Astronomia e Ciências Afins (MAST - Rio de Janeiro/Brasil) e-mail:moema@mast.br}

\begin{abstract}
Resumo
A relação entre o Amazonas e os viajantes é um tema que há muito vem instigando pesquisadores em diferentes disciplinas e em várias partes do mundo. Tal qual este rio, o tema, às vezes, parece inesgotável. 0 presente texto procura contribuir para este enorme mosaico com mais um pequeno fragmento: narrar a viagem de Franz Keller-Leuzinger. Apesar de sua obra já ter sido utilizada em trabalhos sobre a história da ferrovia e fotografia, ainda são escassos os trabalhos dedicados exclusivamente para este personagem, que continua um quase desconhecido. Assim, procuramos dar destaque a este viajante e caminhar no entendimento de questões sobre a percepção da Amazônia no final do Império e sobre os projetos que circulavam visando sua maior integração com o restante do país dentro do esforço de construção de um sentido de nacionalidade que tinha a grandeza do território como base.
\end{abstract}

\begin{abstract}
The relationship between the Amazon and voyagers is a subject that has long been urging researchers in different disciplines and various parts of the world. And this subject sometimes seems endless. This paper seeks to contribute to this discussion with a small fragment: narrating the journey of Franz Keller-Leuzinger. Although his work has already been used in works dealing with the history of the railroad and the photography, there are few studies dedicated exclusively to this character, which remains almost unknown. The main goal of this article is to give him prominence and thus to understand how the Amazon was perceived at the end of the Empire, how its integration to the national territory was conceived and its role in the Brazilian nationalism sentiment based upon the idea of a great territory.
\end{abstract}

\section{Palavras-chaves}

Franz Keller-Leuzinger, viajantes, Amazonas

\section{Keywords}

Franz Keller-Leuzinger, voyagers, Amazonas
1

Para a elaboração deste trabalho contei com a colaboração de colegas na discussão de ideias e indicação bibliográfica que tornaram este texto possivel. Assim, sou intensamente grata a Robert Wegner, Joaquim Marçal Ferreira de Andrade e Frank Stephan Kohl.
DOI - http://dx.doi.org/10.1590/2236-463320130606

Almanack. Guarulhos, n.06, p.81-94, 2 semestre de 2013 
2

Sobre este ponto especifico ver VERGARA, Moema de Rezende. A divulgação da ciência e a ideia de território na Primeira República: a fase de José Verissimo da Revista Brasileira. In: HEIZER, Alda; VIDEIRA, António Augusto Passos (org). Ciência, Civilização e República nos Trópicos. Rio de Janeiro: MAUAD; FAPERJ, 2010. p.137-156.

VASQUEZ, Pedro Karp. Fotógrafos Alemães no Brasil do século XIX. São Paulo: Metalivros, 2000. p.77.

FERREIRA, Orlando da Costa. Imagem e Letra. São Paulo: Editora da Universidade de São Paulo, 1994. p.192.

FERREZ, Gilberto. A fotografia no Brasil: 1840-1900. 2a edição. Rio de Janeiro: FUNART, 1985. p.60.

6

SENNA, Ernesto. O Velho Comércio do Rio de Janeiro. $2^{\text {a }}$ edição. Rio de Janeiro: G Ermakoff, 2006. p.102.

7

Cf. KOHL, Frank Stephan. Um jovem mestre da fotografia na Casa Leuzinger. Cadernos de Fotografia Brasileira/IMS, n.3, p.185-214, 2006.

\section{Uma apresentação}

Ao pesquisar periódicos dedicados à divulgação da ciência no século XIX, deparei-me com uma nota sobre a exploração de Franz Keller-Leuzinger aos rios Amazonas e Madeira. Nestes periódicos, principalmente a partir dos anos de 1870 até o início da República, cientistas e literatos ${ }^{2}$ postavam-se lado a lado exigindo do Estado melhores condições para ampliar o conhecimento sobre o território nacional. Estes intelectuais se valiam de uma retórica de forte cunho nacionalista baseada na grandeza do território e de suas riquezas (reais e imaginadas) para edificar o sentimento de "brasilidade". Em meio a esta pesquisa, foi despertado em mim o interesse por Franz Keller-Leuzinger e sua viagem ao Amazonas, que surgiu como uma instigante oportunidade para estudar um dos momentos mais estimulantes da história sobre a conquista das fronteiras ocidentais no Brasil. Além disso, esta viagem oferece uma ótima oportunidade para ver as representações do Amazonas no Império, por ter gerado publicações nacionais e internacionais ricamente ilustradas. Assim, tendo aquele personagem como guia, investiguei o contexto que motivou sua viagem e os conhecimentos científicos que foram acionados ao longo de seu percurso.

A seu respeito, sabe-se que nasceu em Mannheim na Alemanha em 1835. Era desenhista, cartógrafo, engenheiro e pintor e sua educação artística ocorreu em Dürsseldorf. Chegou ao Brasil em 1857 com seu pai Joseph e irmão Ferdinand Keller e estabeleceram-se no Paraná onde junto com seu pai realizou trabalhos de exploração dos rios Tibagí e Paranapanema. Em 1865 integrou-se à Expedição do Avaí, quando produziu aquarelas da região. ${ }^{3}$ Em 1867 casou-se com a filha do impressor e livreiro George Leuzinger, Sabine Chiristine, e a partir de então adotou o nome de Keller -Leuzinger. No mesmo ano, ele e seu pai foram comissionados pelo Governo Imperial com o objetivo de realizar um estudo para a construção de melhorias para a navegação e de uma ferrovia ao longo do rio Madeira, no vale do Amazonas. ${ }^{4}$ Cabe ressaltar que foi precisamente esta missão que 0 notabilizou através de seus escritos e desenhos. Segundo ele, a repercussão de seu relato sobre o Amazonas e o Madeira foi de tal ordem que o celebre explorador Schweinfurth havia Ihe convidado para realizar o mapa topográfico do Alto Nilo.

Terminado os trabalhos de exploração do rio Madeira, Franz Keller-Leuzinger fixou morada no Rio de Janeiro e colaborou no ateliê tipográfico de seu sogro. ${ }^{5}$ A Casa Leuzinger fechou este ateliê em 1871 e passou a dedicar-se somente a tipografia. ${ }^{6}$ Franz Keller-Leuzinger retornou em 1873 à Europa para tratar da saúde, fixando residência na cidade alemã de Karlsruhe. Segundo Frank Kohl, ele havia contraído malária no Amazonas e justamente por isto não pode aceitar o convite do coronel americano Georg Earl Church (1835-1910) para participar da construção da ferrovia Madeira-Mamoré, que utilizou os dados levantados pelos Kellers naquela região. ${ }^{7}$

Em 1876, aproveitando a passagem de Pedro II à Alemanha, Franz Keller-Leuzinger Ihe escreveu uma carta, na qual expunha os planos que o animavam a retornar ao Brasil. Estes projetos não eram nada modestos: ele pleiteava receber o monopólio para a exploração do sal no Paraná, bem como se oferecia como intermediário na venda de pólvora alemã para o Império, e expressava sua intenção de voltar ao Brasil como engenheiro, uma vez que na Alemanha vivia apenas de seus trabalhos artísticos: 
Carta de Franz Keller-Leuzinger a D. Pedro II, 29 de julho de 1876. Seção de Manuscritos da Biblioteca Nacional.
Cf. KANTOR, Íris. Usos diplomáticos da ilha-Brasil, polêmicas cartográficas e historiográficas. Varia História, vol.23, n.37, p.70-80, 2007 e MAGNOLI, Demétrio. 0 Estado em busca do seu território. Terra Brasilis, n.4-5, p.27-44, 2002-2003.

10

DAVIDSON, David Michel. Rivers and Empire: the Madeira Route and the Incorporation of the Brazilian Far West, 1737-1808. Yale University, Ph. D, 1970.

11

Cf. CINTRA, Jorge Pimentel. 0 Mapa das Cortes: perspectivas cartográficas. Anais do Museu Paulista, vol.17, n.2, p.63-77, 2009.

12

DAVIDSON, David Michel. Op. Cit., p.2-3.
Voltando desse modo outra vez as belas praias da Terra de Santa Cruz, isto é, acompanhando em pessoa um carregamento de pólvora e se necessário fosse de armamento ao Rio de Janeiro. V. M. I. dignasse talvez de encarregar-me outra vez com trabalhos técnicos como antigamente.

Me seja permitido, afora os trabalhos de exploração dos rios, alinhamento de estradas e caminhos de ferro e o levantamento de mapas geográficos, citar a elaboração de projetos de abastecimento da capital com água potável, que dia a dia fica mais urgente. ${ }^{8}$

$\mathrm{Na}$ carta, constatamos que suas ambições empresariais rivalizavam com as científicas, mas ele claramente se via como um homem de ciência e queria ver seu nome ao lado dos demais cientistas como o geólogo americano Charles F. Hartt (1840-1878). Keller-Leuzinger afirmava também que fora encorajado pelo antropólogo alemão Rudolf Virchow (1821-1902) a continuar seus trabalhos científicos. Neste sentido, desejava estudar "tudo o que o vasto Imperio encerra ainda de curioso e de interessante para 0 mundo científico". Ao que tudo indica, estes projetos não sairam do papel. Ele visitou o Brasil nos anos de 1880 e retornou à Alemanha, onde faleceu em Munique em 1890.

\section{O Amazonas, o Império e a viagem de Franz Keller-Leuzinger}

Um dos desafios do Império do Brasil foi o efetivo conhecimento do território herdado de sua antiga metrópole. A conquista do "corpo da nação" se constituiu por diversos meios, tais como a delimitação de fronteiras, 0 inventário de seus primeiros habitantes e a classificação de sua natureza e seu potencial econômico; todas, práticas que contribuíram para forjar o espírito de nacionalidade brasileiro. Este processo reforçou uma mitologia sobre o Brasil, como a "terra da abundancia" e de um país formado por uma "fronteira natural" conferida pelas bacias do Prata e do Amazonas. Este desiderato fora vital para o fortalecimento do Estado e de instituições dedicadas ao inventário científico de seu território, tanto no período colonial como no imperial. ${ }^{9}$

A cartografia é locus no qual este ideário se manifesta concretamente, e lá estão estampadas as contradições de um país que herdou um território que era mais um conceito do que um espaço efetivamente delimitado e conhecido. Em outras palavras, as extremidades norte e sul e a costa eram conhecidas, contudo, ainda restava desconhecida a banda ocidental ${ }^{10}$, precisamente a região explorada por Franz Keller-Leuzinger.

Importante destacar que Keller-Leuzinger não foi o primeiro a explorar o Madeira. Este rio fora conquistado, na Colônia, pela ação de bandeirantes e sertanistas, alargando a linha do Tratado de Tordesilhas. Ele era utilizado para o escoamento de metais preciosos no Mato Grosso, bem como para a integração daquela região ao restante do país, apesar das dificuldades de navegação. 0 rio Madeira permaneceu como importante via mesmo após o declínio da produção aurifera, no século XVIII. Assim, podese ver a emergência dos rios como um instrumento geopolítico no âmbito da diplomacia luso-brasileira. ${ }^{11}$

Contudo, segundo David Davidson, a ocupação não seria o único meio para tornar aquelas terras pertencente à Coroa. Os embaixadores portugueses teriam que garantir a legitimidade destas conquistas. A soberania portuguesa no Amazonas se deu pelos embates dos agentes locais na América, bem como na esfera diplomática na Europa, com os argumentos de uti possidetis $^{12}$. Desta forma, foi a partir do Tratado de Madri de 1750,que o rio 
Cf. PEIXOTO, Renato Amado. A máscara da medusa: A construção do espaço nacional brasileiro através das corografias e cartografia no século XIX. Tese (Doutorado em História Social). Instituto de Filosofia e Ciências Sociais da Universidade Federal do Rio de Janeiro, Rio de janeiro, 2005

MARTIN, Percy Alvin. The Influence of the United States on the Opening of the Amazon to the World's. The Hispanic American Historical Review v.01, n.02, p.146-162, May/1918. Disponível em $<$ http://www.jstor.org/stable/2506100>. Acessado em 13/11/2012.

15

KELLER-LEUZINGER, Franz. Amazon and Madeira Rivers: sketches and descriptions from the notebook of an Explorer. Filadélfia, J. B. Lippincott, 1875. p.33.

16

KELLER, José; KELLER, Francisco. Relatório da Exploração do Rio Madeira na parte compreendida entre a cachoeira de Santo Antônio e a barra do Mamoré. In: BRASIL. Relatório do Ministério da Agricultura,

Comércio e Obras Públicas, 1869. Disponivel em $<$ http://www.crl.edu/brazil/ministerial >. Acessado em 13/03/2013, p.2

17

$\mathrm{CHURCH}$, George Earl. Explorations made in the Valley of the River Madeira, from 1749 to 1868. London: Published for the National Bolivian Navigation Company, 1875.

18

Após a falência do projeto de construção da ferrovia Madeira-Mamoré no início do século $X X$, a saída boliviana para escoar sua produção para o mercado internacional foi pelo Pacífico mediante ligações ferroviárias com os portos do Chile e Peru. Cf. HARDMAN, Francisco Foot. Trem Fantasma: a ferrovia Madeira-Mamoré e a modernidade na selva. São Paulo: Companhia das Letras, 2005. p.161.

19

FIFER J. Valerie. The Empire Builders: A History of the Bolivian Rubber Boom and the Rise of the House of Suarez. Journal of Latin American Studies, n.2, p.113-146, 1970, especialmente p.117.

20

Cf. TOCANTINS, Leandro. Formação Histórica do Acre. Vols. I e II. Brasilia: Edições do Senado Federal, 2009.
Madeira torna-se incontestavelmente português e mais tarde brasileiro. ${ }^{13}$ Se em meados do século XIX não havia dúvidas de que o rio Madeira era brasileiro, este ainda deveria ser mais bem explorado.

A conjuntura da expedição de Franz Keller-Leuzinger também estava marcada pela abertura do rio Amazonas para outras nações em 7 de setembro de 1866, no decreto imperial n. 3749. Em meados do século XIX o Império sofreu pressões internacionais, vindas principalmente dos Estados Unidos, para abrir a navegação do Amazonas. A concessão de liberdade de navegação só ocorreu após intensos debates iniciados pelo impacto do "Memorial de Memphis", publicado em 1853 pelo Tenente da Marinha Americana Matthew Fontaine Maury, que rogava para que seu governo tomasse providências, com o uso de força se preciso fosse, para angariar a almejada liberdade de navegação a todas as nações no Amazonas e em seus afluentes. A repercussão da propaganda de Maury no Brasil causou protestos indignados na imprensa, mas fez com que crescesse os argumentos da importância da abertura do Amazonas para a projeção de uma imagem positiva do país em âmbito internacional, capitaneadas principalmente por Tavares Bastos. ${ }^{14}$ Keller-Leuzinger reforçava estes argumentos ao afirmar que a abertura daquele rio significava um avanço do governo brasileiro contra "resquícios do monopólio colonial"15. Além disso, logo em seguida, foi assinado em 1867 o Tratado de Ayacucho com a Bolívia que definia os limites entre os dois países. Assim, segundo a portaria de 10 de outubro do mesmo ano, Franz Keller-Leuzinger e seu pai, foram

\begin{abstract}
incumbidos pelo governo imperial de explorar o rio Madeira na parte encachoeirada dele, desde Santo Antonio até a barra do rio Mamoré, e de elaborar os projetos mais apropriados para o melhoramento dessa importante via de comunicação com a província de Mato Grosso e a república da Bolívia (grifo nosso). ${ }^{16}$
\end{abstract}

Outrossim, pode-se interpretar esta viagem como uma investida do Estado Imperial para resolver a questão herdada da colônia, ou seja, a exploração dos rios Amazonas e Madeira e a integração do país, levando em consideração a comunicação com Mato Grosso. A convergência destes eventos com da exploração da borracha, cacau, café, tabaco e quina, produtos de grande demanda comercial, formaram os elementos motivadores para a organização desta expedição. ${ }^{17}$ Desta forma, criar vias de ligação desta área com o restante do globo não era só um problema de integração do Império brasileiro. Era, igualmente, o meio para escoar valiosas matérias-primas para o mercado internacional. Também era fundamental para a Bolívia ter outros canais para escoar sua produção. Uma vez que transpor os Andes era inviável, a solução articulada naquele momento seria uma rota pelo Amazonas. ${ }^{18}$

$\mathrm{Na}$ década de 1860, já se observava seringueiros trabalhando ao longo do baixo Purus e Madeira, e durante a década seguinte, os brasileiros e bolivianos lá acamparam enquanto a fronteira entre os dois países permanecia incerta. Estes seringueiros eram de origem indígena e não provenientes do Nordeste deslocamento que só ocorrerá na década seguinte. Para Valerie Fifer, uma das consequências do Tratado de 1867 foi o afastamento dos bolivianos do Baixo Madeira, deixando este para a ocupação brasileira. A povoação boliviana, por sua vez, se concentrou no Alto Madeira, obedecendo a nova linha oblíqua que cortava da nascente do rio Javary (ainda inexplorado naquele momento) até a latitude $10^{\circ} 20^{\prime}$ sul na confluência do Madeira-Mamoré. ${ }^{19}$ Em outras palavras, esta área era brasileira, justificando ainda mais o esforço do governo em explorar esta região pouco conhecida e povoada, Ultima Thule do Brasil. ${ }^{20}$ 
KELLER-LEUZINGER, Franz. Amazon and Madeira Rivers... Op. Cit., p.42.
Em novembro de 1867, Franz Keller-Leuzinger saiu do Rio de Janeiro subindo pela costa até chegar ao Pará, de onde iniciara sua expedição no Amazonas. Foi na cidade de Manaus que ele organizou a viagem aos vales dos rios Madeira-Mamoré. 0 carregamento, dividido em sua frota de sete canoas, consistia em provisões para quatro meses, ferramentas para conserto das canoas, cordas, tendas, armas, medicamentos e presentes para as "tribos selvagens e semisselvagens" dos vales. ${ }^{21}$ A tripulação era formada por seu pai, Joaquim Manuel da Silva - engenheiro brasileiro, um técnico assistente, um comerciante italiano vindo da Bolívia, um alemão do qual só se referiu pelas iniciais P.v.S., descrito como um jovem aventureiro experiente em viagens como aquela em outras partes do mundo, além de 70 índios bolivianos das missões do Mamoré e pilotos de 7 canoas, 8 brancos. Os índios eram remeiros, essenciais para a exploração e foram conseguidos com a ajuda do vicecônsul boliviano que estava em Manaus. Ao acompanhar esta expedição ao longo dos rios, a compreensão do termo fronteira se amplia, na medida em que o mesmo pode significar uma área de limites fluidos com práticas sociais e culturais próprias e que não deve ser confundido com limites territoriais.

Mapa de Franz Keller-Leuzinger reproduzindo o percurso de sua viagem, no livro Vom Amazonas und Madeira.

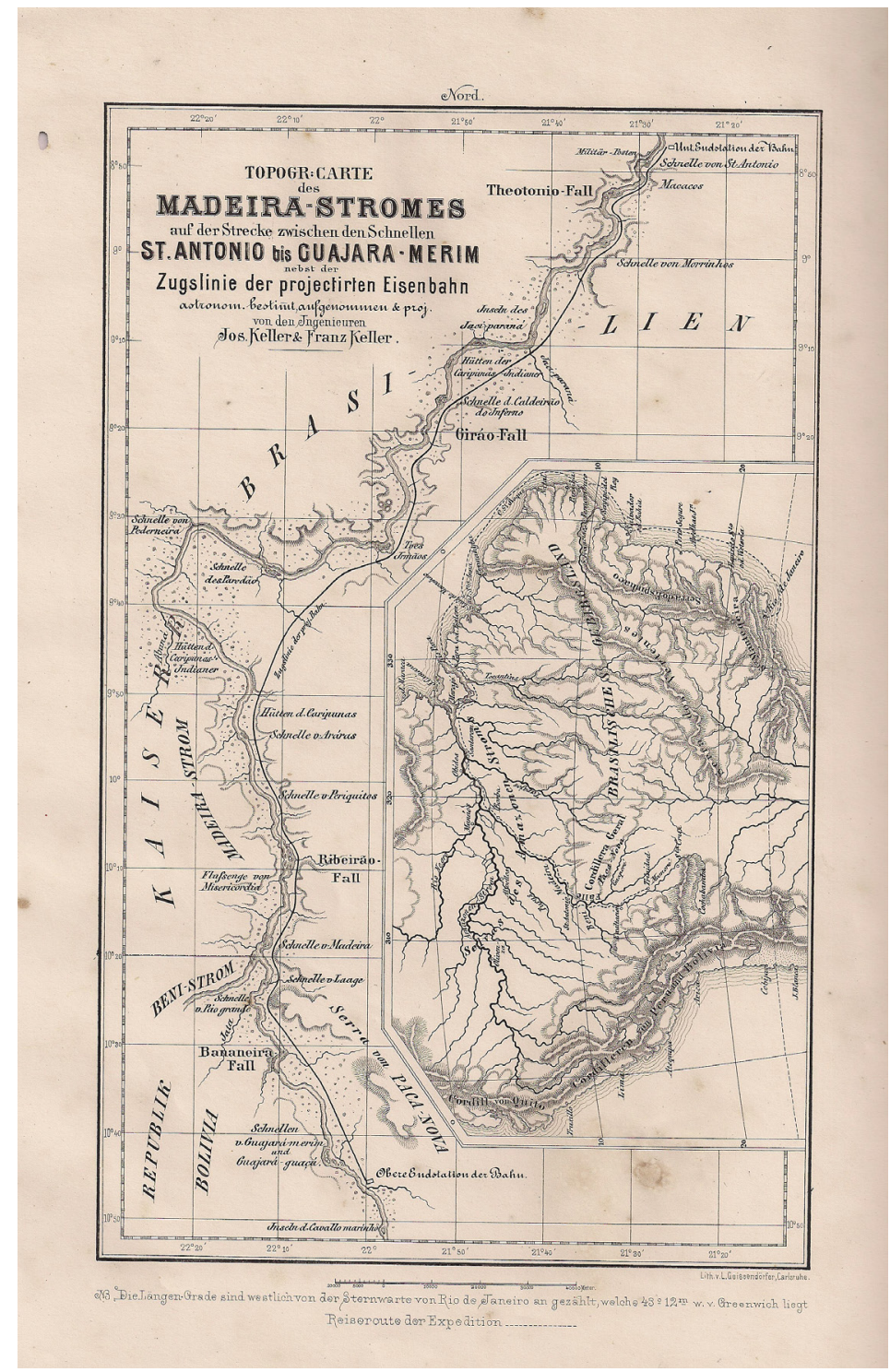

Fonte: Biblioteca do Instituto Histórico e Geográfico Brasileiro. 
22

KELLER, José; KELLER, Francisco. Exploracion del Rio Madeira en la parte comprendida entre La Cachuela de San Antonio y La embocadura del Mamoré. La Paz: Imprenta de la Union Americana - por Cézar Sevilla, 1870. p.72.

23

Idem. Relatório da Exploração do Rio Madeira... Op. Cit., p.5.

24

KELLER-LEUZINGER, Franz. Amazon and Madeira Rivers... Op. Cit., p.57.
No caso desta expedição, a missão principal era elaborar estimativas dos custos para a construção de uma ferrovia ao longo daqueles rios e obras de canalização, bem como a construção de vinte planos inclinados entre as cachoeiras de Santo Antonio e Guajará. Em seu relatório, os Kellers concluíram que o sistema de transporte baseado em canoas movidas por remadores inviabilizava por completo a possibilidade de desenvolvimento do futuro comércio da região. Por isto a construção de planos inclinados que ampliaria a capacidade de oito para 30 toneladas de carga. Para o autor, a população indígena que vivia "destruída fisicamente" por estes trabalhos, com as obras de engenharia, poderiam se dedicar à agricultura e a indústria. ${ }^{22}$

A expedição chegou ao rio Madeira no mês de julho de 1868 e encontrou o rio $4 \mathrm{~m}$ mais baixo que o usual, "os bancos de areia nas margens convexas, apareciam de mais a mais" 23 . Em sua passagem por aquele rio, Keller-Leuzinger registrou a queixa dos seringueiros do Madeira de que os bolivianos frequentemente não levavam consigo a quantidade precisa de mantimentos e roubavam constantemente as roças que margeavam o rio. Este relato é interessante para relativizar a ideia da Amazônia como terra da abundancia (imagem presente até hoje). Se o viajante não levasse consigo as provisões necessárias, morreria de fome, pois em determinados setores da floresta não há frutos nem peixes.

A geografia do Alto Madeira conta com uma série de cachoeiras que marcam a agitada confluência com o Mamoré. Quando a comitiva lá chegou tiveram que descarregar e subir as canoas com ajuda de cordas. Essa penosa tarefa foi repetida várias vezes ao longo da jornada. Entre as cachoeiras Morrinhos e o Caldeirão do Inferno, observaram canoas dos índios Caripunas dos quais Keller-Leuzinger já havia tido notícia de acirrados conflitos com os brancos, mas ele não teve problemas, chegando a trocar presentes por milho e raizes de mandioca. ${ }^{24}$

A cachoeira Caldeirão do Inferno possuía a pior reputação por ter provocado a morte de vários navegantes pela força de sua correnteza, quebrando as embarcações contra as pedras, e sendo as mesmas tragadas por redemoinhos. Em seguida, a comitiva atingiu a parte inferior da cachoeira do Ribeirão, formada por cinco cachoeiras, que segundo Keller-Leuzinger possuiam as quedas d'água mais notáveis, chegando a 13 metros de altura. Estas descrições, além de conferir uma dramaticidade ao relato, justificariam a recomendação de construção de planos inclinados para viabilizar a navegação destes rios encachoeirados expresso no relatório entregue ao Ministério da Agricultura.

Quando estava no rio Beni, nas proximidades da cachoeira Guarajá-Guassú, Keller-Leuzinger encontrou uma grande comitiva boliviana que carregava sebo e couros e the pediu para enviar ofícios e cartas para o Pará e Rio de Janeiro. Nesta passagem, nota-se como a comunicação se dava em uma área afastada de centros urbanos e desprovida de rede telegráfica. A correspondência de Keller-Leuzinger provavelmente não chegou ao seu destino, pois em seu relatório ele afirmava que a falta de notícias provocou rumores de que a expedição havia fracassado e que a tripulação havia desaparecido.

0 trabalho de campo da expedição consistia em fazer levantamentos hidrográficos, hipsométricos e determinação de coordenadas geográficas a partir de observações astronômicas em uma região pouco mapeada. Para executar o levantamento das coordenadas geográficas, era necessário 
0 cálculo da longitude é obtida através da diferença de tempo da passagem de uma estrela através do meridiano em dois lugares determinados. Em outras palavras, observa-se 0 trânsito da estrela num lugar e depois em outro lugar e, com o apoio de um catálogo celeste, pode-se de determinar a longitude de um determinado ponto no globo.

26

Pode-se calcular a longitude levando-se em consideração que cada hora representa $15^{\circ}$. Ou seja, no caso do Rio de Janeiro em relação a Greenwich, temos $3 \mathrm{~h}$ a menos de diferença, o que significa que estamos a $45^{\circ}$ de longitude oeste. Cf. VERGARA, Moema de Rezende.

Ciências, fronteiras e nação: comissões mistas de demarcação dos limites territoriais entre Brasil e Bolivia, 1895-1901. Boletim do Museu Paraense Emílio Goeldi, Ciências Humanas, vol.5, n.2, p.345-361, 2011.

27

CRAIG, Nevile. Estrada de Ferro MadeiraMamoré: história trágica de uma expedição, 1947. Disponivel em http://www.brasiliana.com. br/brasiliana/colecao/autores/140/Neville-BCraig. Acessado em 14/03/2013, p.31.

KELLER-LEUZINGER, Franz. Amazon and Madeira Rivers... Op. Cit., p.2.

KELLER, José; KELLER, Francisco. Exploracion del Rio Madeira... Op. Cit., p.19.

30

KELLER-LEUZINGER, Franz. Amazon and Madeira Rivers... Op. Cit., p.155.

31

KELLER, José; KELLER, Francisco. Exploracion del Rio Madeira... Op. Cit., p.26 realizar a determinação das longitudes. ${ }^{25}$ Keller-Leuzinger afirmou que os seus cronômetros de marinha, instrumento fundamental para o transporte da hora ${ }^{26}$ no cálculo da longitude, já haviam se mostrado defeituosos em Manaus. Um expedicionário mais experiente o tinha prevenido de que estes delicados instrumentos sofreriam com as condições instáveis da viagem em canoas, e os tornariam ineficazes na determinação das longitudes. Assim para resolver este problema, ele se baseou nas diferenças lunares como forma de obter estas coordenadas. Este método, segundo ele, não possibilitou que todas as medições tivessem a mesma precisão, uma vez que as observações dependiam das condições meteorológicas.

No relatório de 1869, ele descreveu como fez suas medições: as latitudes foram determinadas pela altura do sol e das estrelas, tomadas quase sempre nos lugares onde acamparam. As observações noturnas foram favorecidas por um céu sem nuvens principalmente nas estações secas. Os instrumentos usados foram um círculo de reflexão de Casella e dois sextantes com horizontes artificiais. Também utilizou um micrômetro de Rychon e uma bússola prismática para estabelecer o curso dos rios. Entretanto, não realizou triangulações por falta de pessoal e em virtude da dificuldade de efetivar os trabalhos de campo necessários na densa floresta. Segundo Neville Craig, o engenheiro alemão realizou um valioso trabalho ao compilar mapas do rio Madeira:

Keller reuniu vasta cópia de informes sobre a região e confirmou, em grande parte, as ideias expendidas pelo Tenente Gibbon. Compilou mapas do rio, em escala grande, e procedeu a cuidadosas sondagens, mas, não podendo contar com seus cronômetros que se estragaram pelo excesso de uso e obrigado a valer-se de observações lunares para cálculos de longitude, verificou-se, mais tarde, que havia diferenças consideráveis em seus mapas, na direção leste-oeste. ${ }^{27}$

A altitude do relevo foi feita por barômetros e hipsômetros. Junto com os instrumentos científicos, pode-se afirmar com bastante segurança que ele levou consigo o Anuário do Imperial Observatório para os cálculos geodésicos, uma vez que o meridiano de referência de suas coordenadas é o Rio de Janeiro. Uma referência ao Observatório do Rio de Janeiro aparece em uma nota no livro de 1874 ao descrever o clima da capital do Império, afirmando que a cidade deveria ser mais quente do que dizia as estatísticas oficiais, uma vez que o Observatório (lugar das aferições meteorológicas) ficava no alto Morro do Castelo "varrido pela fria brisa do mar"28.

A parte mais ocidental que a expedição alcançou foi Exaltacion, na Bolívia. Nesta cidade, Keller-Leuzinger buscou mantimentos e mais remadores para fazer sua viagem de volta e lá visitou uma antiga missão jesuítica. Segundo ele, foi no final do século XVII que se fundou esta missão nas margens do Mamoré e terra dos índios Cayubabas. ${ }^{29}$ Para este engenheiro alemão, a catequese era a única alternativa para integrar os índios à civilização, uma vez que após o contato com os brancos, de forma geral, a vida dos índios estaria condenada. Em suas palavras: "por uma aniquilação moral e física, sendo as missões religiosas tanto do sul como do norte do país a salvação dos indígenas ao prevenirem de um destino de maior exploração" ${ }^{30}$.

Em novembro de 1868, findava a expedição e já tendo chegado em Manaus, Keller-Leuzinger afirmou que teve que "devolver as armas e demais utensílios" quando se despediu do presidente da província, sem esclarecer precisamente que utensilios eram estes..$^{31}$ Interessante notar que a 
BENÉVOLO, Ademar. Introdução à História Ferroviária do Brasil. Recife: Edição Folha da Manhã, 1953. p.587.

34

FERREIRA, Manuel Rodrigues. A Ferrovia do Diabo. São Paulo: Ed. Melhoramentos, 2005. p.67.

35

Diário Oficial do Império do Brasil, de 24 de janeiro de 1869. expedição foi armada para a viagem, mas não há registro de confrontos em seu relato. No dia 4 de janeiro de 1869 chegou ao Rio de Janeiro, de onde saíra quatorze meses antes, menos queimado pelo sol e menos enfraquecido pelas febres. ${ }^{32}$

Em 1869, foi publicado o relatório final, sob o título "Relatório da Exploração do Rio Madeira na parte compreendida entre a cachoeira de Santo Antônio e a barra do Mamoré", assinado por José e Francisco Keller. Este documento é bastante citado nos trabalhos subsequentes sobre a ferrovia Madeira-Mamoré.

Na historiografia do século XX, a ida dos Kellers ao Amazonas nem sempre foi avaliada positivamente pelos historiadores. No livro Introdução à História Ferroviária do Brasil, Ademar Benévolo enquadrou os Kellers como fazendo parte de uma "invasão de técnicos estrangeiros no chamado Segundo Império"33. Para este autor, o Governo Imperial legitimou e incentivou a entrada de estrangeiros por meio de um decreto do Ministério da Agricultura de 1862, que permitia a nomeação de engenheiros em detrimento dos técnicos brasileiros que, segundo Benévolo, poderiam ter realizado tal empreitada.

Na mesma linha de argumentação, encontramos Manoel Rodrigues Ferreira, para quem a escolha dos Kellers se devia ao "complexo de que sofriam os dirigentes brasileiros relativos aos técnicos estrangeiros" ${ }^{34}$. Ferreira também fez um balanço pouco positivo de seus trabalhos: segundo ele, aqueles engenheiros estiveram apenas quatro meses nas cascatas, o que não daria tempo para fazer um projeto detalhado das soluções propostas em seu relatório final. Os custos que apresentavam eram nada mais que simples estimativas, sem nenhuma base na realidade. Para a ferrovia estimam o custo de 8.500:000 $\$ 000$ e para os planos inclinados 21.000:000 \$000. Contudo, para este autor, o mérito desta empreitada estaria nas conclusões: o traçado da ferrovia deveria acompanhar o trecho das cachoeiras e ela deveria passar, obrigatoriamente, em frente à foz do Beni, a fim de coletar o comércio que descia por este rio.

Conforme afirmamos anteriormente, estes dados foram transferidos para Georg Earl Church, contratado pelo governo brasileiro para a construção da ferrovia (1869). Ele obteve de Pedro II a autorização pretendida e mais a concessão de explorá-la durante cinquenta anos, fundando, para tal, a empresa Madeira and Mamoré Railway. No Diário Oficial do Império lê-se:

\footnotetext{
Depois que o governo brasileiro franqueou o Amazonas e seus principais afluentes às bandeiras amigas, uma grande revolução econômica começou a desenvolverse, lenta a princípio, prometendo tomar proporções incomensuráveis no futuro. A primeira consequência notável do ato magnânimo do governo brasileiro, foi o contrato que acaba de celebrar o governo da Bolívia com o engenheiro americano George E. Church para a navegação do Mamoré e outros afluentes do Madeira que pertencem à República, podem o empresário de acordo com o governo brasileiro, executar também a grande obra da estrada de ferro que deve evitar as cachoeiras desse rio. ${ }^{35}$
}

Os desdobramentos da expedição de Keller-Leuzinger não foram muito felizes. Tendo o governo boliviano como avalista, Church conseguiu, em 1872, o empréstimo de um milhão e setecentas mil libras dos banqueiros ingleses. No período de 1872-1879 contratou quatro empresas construtoras: duas inglesas e duas norte-americanas as quais por adversas circunstâncias fracassaram na tentativa de construir a ferrovia. Em 18810 
FORTE, Ernesto Mattoso Maia. Do Rio de Janeiro ao Amazonas e Alto Madeira. Itinerário e Trabalhos da Comissão de Estudos da Estrada de Ferro Madeira Mamoré. De um membro da mesma comissão. Rio de Janeiro: Typ. Soares \& Niemeyer, 1883.

37

Cf. HARDMAN, Francisco Foot. Op. Cit.

38

FERREIRA, Orlando da Costa. Op. Cit., p.192.

39

KELLER-LEUZINGER, Franz. Amazon and Madeira Rivers... Op. Cit., p.20.

40

Ibidem, p.133

41

Ibidem, p.117.

42

KELLER-LEUZINGER, Franz. Amazon and Madeira Rivers... Op. Cit., p.133. governo brasileiro cancelou a concessão dada ao coronel americano, como informou Ernesto Mattoso Maia Forte em seu livro "Do Rio de Janeiro ao Amazonas e Alto Madeira" de 1883, membro da comissão de Church. ${ }^{36}$ Esta ferrovia só iria ser iniciada no começo do século XX sem, contudo, chegar a ser eficazmente utilizada. ${ }^{37}$

\section{0 livro Vom Amazonas und Madeira}

Em 1874 surgiu o seu livro Vom Amazonas und Madeira na Alemanha, com 68 belas gravuras executadas no Xylographische Anstalt Von A. Closs, de Stuttgart, com desenhos de seu irmão Ferdinand, feitos a partir dos esboços de Franz Keller. ${ }^{38} 0$ livro se divide em sete capítulos e traz um anexo e um mapa. Interessante notar que o relato da viagem em si termina no segundo capítulo, amplamente baseado no Relatório de 1869. 0 autor reservou o restante da obra para se dedicar a descrição da vida na região, incluindo caça, culinária, vegetação, pesca, as tribos indígenas do Vale do Madeira e a catequese dos jesuitas.

A sua principal chave de leitura estava dada na introdução: a narrativa era construída na tentativa de responder por que o Brasil, um país rico pelas "dádivas da Natureza", não atingia "o mais alto grau de desenvolvimento"39. Esta formulação incluía a natureza com suas potencialidades na equação da civilização e progresso. Assim, cabe notar a dinâmica estabelecida entre homem e natureza no capítulo $V$, A vegetação da floresta virgem no Amazonas e Madeira. Lá havia a seguinte descrição da passagem da floresta Amazônica: "(...) a Natureza, imperturbada pelo homem, criou seus próprios prodígios, na qual não há separação ente suas crianças do solo maternal, e onde nenhum telhado de vidro intervém entre eles o éter azul!"40.

Entretanto, longe estava sua narrativa de uma imagem edênica do Amazonas. Dentre as riquezas da floresta estava elencada a seringueira, que fornece o látex para a borracha utilizada na confecção de artigos que iam das galochas aos protetores dos fios do telégrafo, cuja potencialidade de usos ainda não haviam se esgotado, segundo o autor. Para ele, infelizmente não havia nenhum esforço de um cultivo ordenado e concentrado desta árvore afirmando que toda borracha exportada no Pará provinha da floresta. Demonstra uma preocupação com a exploração e o consequente esgotamento deste recurso. Keller-Leuzinger fica chocado com a combinação da indolência do mestiço e a falta de visão do governo e denunciava que isto acarretaria na diminuição da produção e era só questão de tempo, como de fato ocorreu para que a Europa e a América do Norte (então maiores importadores do Brasil) achassem um substituto para aquela cara resina. ${ }^{41}$

0 engenheiro alemão via com pessimismo os índios do Amazonas. Com clara influência de um determinismo mesológico, ele sentenciava que somente os "peles vermelhas" (palavras dele) do México, América Central e Peru passaram da condição de nômades para criadores de gados e agricultores e assim atingiram o mais alto grau de civilização, enquanto o resto da América, imersa na floresta que inviabilizava a criação de gado, reduzia a agricultura ao mínimo levando à dispersão necessária das tribos, e, por conseguinte, fazia com que o desenvolvimento se tornasse inviável. ${ }^{42}$ Contudo, a solução para ele não estaria na eliminação dos indígenas como estava ocorrendo nos Estados Unidos, mas na miscigenação. Segundo Keller-Leuzinger, os indígenas eram o grupo humano mais adaptado aos trópicos. Assim, uma nova geração deveria surgir fruto de um processo de "amalgamação" e produziria uma raça estável e adaptada ao clima que, se não fosse dotada 
CUNHA, Euclides. À Margem da História. Rio de Janeiro: Academia Brasileira de Letras, 2005.

44

KELLER-LEUZINGER, Franz. Voyage d'Exploration sur l'Amazone et le Madeira. Le Tour du Monde, 1874, p.369-416. Disponivel em <http://gallica. bnf.fr/>. Acessado em 13/03/2013.

45

RIAUDEL, Michel. 0 palimpsesto: o Amazonas de Júlio Verne, das fontes à ficção. Revista da USP, p.66-74, 2007, especialmente p.67.

46

RECLUS, Élisée. Nouvelle Géographie Univesalle la terre et lês hommes. Vol. XIX - Amérique du Sud. Paris: Librairie Hachette et Cie, 1894.

47

Esta era uma publicação quinzenal impressa pelo Imperial Instituto Artístico fundado por Henrique Fleiuss. 0 Instituto foi aberto em 1860 e durou até 1878, quando faliu justamente por editar uma revista de projeto gráfico ambicioso, a Ilustração Brasileira. plenamente da capacidade de trabalho dos europeus, pelo menos poderia conviver pacificamente, pois, apesar de não ter sofrido com ataques dos índios, ele ouviu inúmeros relatos de conflito entre índios e brancos.

Em meio a esta floresta acontecia uma forma de exploração dos coronéis sobre os coletores que vendiam seu produto por baixo custo 0 qual, por sua vez, era revendido pelo triplo do preço no Pará. Para piorar o quadro, Keller-Leuzinger afirmava que a borracha raramente era paga em dinheiro, mas em provisões, criando um vínculo de servidão que dificilmente era rompido, mantendo esta população de mestiços e índios em permanente estado de tutela. Assim, as denúncias de Keller-Leuzinger antecipavam em parte as de Euclides da Cunha em a Margem da História ${ }^{43}$ com relação às condições de trabalho nos seringais.

\section{A circulação da obra de Franz Keller-Leuzinger}

Em 1874, mesmo ano de lançamento do livro Vom Amazonas und Madeira, a revista Le Tour du Monde publicou um extenso artigo reproduzindo 23 das 68 xilogravuras originais, traduzido do alemão por J. Gourdault. ${ }^{44} \mathrm{Se}-$ gundo Michel Riaudel, esta obra influenciou o romance La Jangada, 1881, de Júlio Verne. A presença dos relatos de Keller-Leuzinger no livro do autor francês muito provavelmente foi inspirada pelo artigo de Le Tour du Monde como a referência a algumas entidades míticas do Amazonas. Riaudel acreditava que a influência do trabalho de Keller-Leuzinger estava também na força de seus desenhos que acompanhavam o texto, como por exemplo, 0 ataque de jacaré sofrido pelos personagens de Verne no capítulo XVII. ${ }^{45}$ Não só na ficção e nas revistas de divulgação a obra de Keller-Leuzinger estava presente. Anos mais tarde Vom Amazonas und Madeira era largamente utilizado no livro do geógrafo Élisée Reclus, Nouvelle Géographie Univesalle: la terre et les hommes, de $1894 .{ }^{46}$ No capitulo sobre a Amazônia, Keller-Leuzinger fora citado como fonte em vários aspectos etnográficos e de descrição geográfica da região.

A versão para o inglês da primeira edição ocorreu também no mesmo ano de seu lançamento pela editora Chapman and Hall. Em 1875 a obra recebeu uma segunda edição na Inglaterra por James Sprent Virtue, sob o título Amazon and Madeira Rivers: sketches and descriptions from the note-book of an Explorer, sendo que não há registro do tradutor. Na segunda edição inglesa havia uma nota afirmando que houve uma conversão para o sistema de pesos e medidas anglo-saxão e que esta edição fora revisada pelo naturalista Henry Walter Bates da Royal Geographical Society, que também havia estado no Amazonas em 1847. Nos Estados Unidos, foi editada na Filadélfia por J. B. Lippincott. Esta obra é publicada sem o mapa da edição original em alemão. A segunda edição inglesa é comercializada até os dias atuais e é nela que o presente trabalho se baseia.

Até o presente momento, Vom Amazonas und Madeira não foi traduzido para o português. A notícia mais ampla sobre esta expedição no idioma nacional foi editada na luxuosa revista Ilustração Brasileira de Carlos e Henrique Fleiuss. ${ }^{47}$ Nesta revista, a obra do engenheiro alemão surgiu em forma seriada em um conjunto de seis artigos, espalhados entre julho de 1876 e maio de 1877 . Ao longo dos artigos, 22 gravuras permeiam o texto. A ênfase está na descrição dos índios e dos costumes da região visitada:

A indústria do Amazonas é quase toda extrativa, dizem os próprios brasileiros. 0 que significa que esta indústria repousa quase toda em uma espécie de espoliação do 
KELLER-LEUZINGER, Franz. Viagem d'Exploração ao Amazonas e ao Madeira. Parte I. Ilustração Brasileira, n.01, p.5-7, 1 de julho de 1876.

49

FERREIRA, Orlando da Costa. Op. Cit., p.192.

50

ANDRADE, Joaquim Marçal Ferreira de. A trajetória de Henrique Fleiuss, da Semana Ilustrada: subsidios para uma biografia. In: KNAUSS, Paulo et alli (org.) Revistas Ilustradas: modos de ler e ver no Segundo Reinado. Rio de Janeiro: MAUAD; FAPERJ, p.53-66, 2011, especialmente $p .62$

51

CARDOSO, Rafael (org.) Impresso no Brasil (1808-19030): destaques da história gráfica no acervo da Biblioteca Nacional. Rio de Janeiro: Verso Brasil, 2009. p.73.

52

KELLER-LEUZINGER, Franz. Viagem d'Exploração ao Amazonas e ao Madeira. Parte VII. Ilustração Brasileira, n.2, p.340-341, 15 de maio de 1877. território. 0 trabalho do homem representa aí insignificante papel, é tudo devido à exuberância da natureza que fornece um tributo de contínuo renascimento. ${ }^{48}$

Para Orlando da Costa Ferreira, Fleiuss transcreveu o texto na integra da revista francesa Tour du Monde ${ }^{49}$. Com passagens semelhantes e a adoção do mesmo título, "Viagem d'Exploração ao Amazonas e ao Madeira", tradução literal do francês "Voyage d'Exploration sur l'Amazone et le Madeira", esta edição pode ter precipitado a conclusão de Costa Ferreira de que se tratava de uma cópia. 0 que verifiquei após cotejar os dois artigos é que esta afirmação não se sustenta, pois Fleiuss era alemão e não precisaria de uma tradução em francês para publicar o relato de Keller-Leuzinger em sua revista. Cabe acrescentar também que as imagens que ilustraram ambos os artigos eram diferentes.

Segundo Joaquim Marçal Ferreira de Andrade, esta revista fora um importante marco na história da imprensa no Brasil, entre outros motivos por representar a consolidação do emprego da litogravura sobre a xilogravura. 0 modelo da Ilustração Brasileira eram as revistas francesas L'Illustration e a inglesa The Illustrated London News, ambas ricamente ilustradas com xilogravuras de grande formato. A maioria das gravuras da Ilustração Brasileira era importada, poucas sendo produzidas no Rio de Janeiro, e copiadas de fotografias. Para este autor as páginas do artigo de Franz Keller-Leuzinger fora um marco na história do projeto gráfico das páginas das revistas ilustradas do Brasil, "mesmo considerando-se que as matrizes eram alemãs"50.

Rafael Cardoso chamou a atenção para o projeto gráfico destas publicações, vedete da produção editorial do século XIX, lembrando que entre 0 autor e as mãos do leitor estes textos passaram pelos editores e projetistas, o que muitas vezes alterava consideravelmente o conteúdo e a forma da intencionalidade do autor. Cardoso sublinhou em sua análise o caráter inventivo destas iniciativas editorias, que contavam com uma variedade de soluções técnicas empregadas. Isto indicaria um processo de transmissão de ideias dinâmico e autônomo que desmentiria uma concepção corrente da historiografia de que a vida intelectual no Brasil, marcada irremediavelmente pelo atraso, estaria condenada a cópia de centros instalados em outras latitudes. Estes projetos eram "fruto de uma cultura visual e material condicionada por práticas de leitura, venda e coleção" 51 .

Seguindo esta linha de argumentação, é importante dar atenção ao trabalho de Henrique Fleiuss a frente da Ilustração Brasileira e seu trabaIho de divulgação do livro Vom Amazonas und Madeira. Fleiuss fora mais inovador se comparado ao editor francês de Tour du Monde na composição entre texto e imagem, rompendo a linearidade da escrita, ao fazer com que o leitor vagasse com os olhos na página para seguir com a leitura do texto.

No último artigo, Fleiuss inseriu duas imagens que não constavam na obra original com a legenda "Navegação atual no rio Amazonas" em contraste à outra gravura, com os dizeres "Navegação antiga do rio Amazonas" 52 . Esta última se assemelha a uma que consta no livro, mas um olhar mais atento percebe facilmente a diferença. No livro, esta imagem tem por objetivo ilustrar a variedade de tipos de embarcações que circulavam no rio Amazonas, tais como a coberta, o batelão, o igarité e a montaria. 
Navegação antiga no rio Amazonas

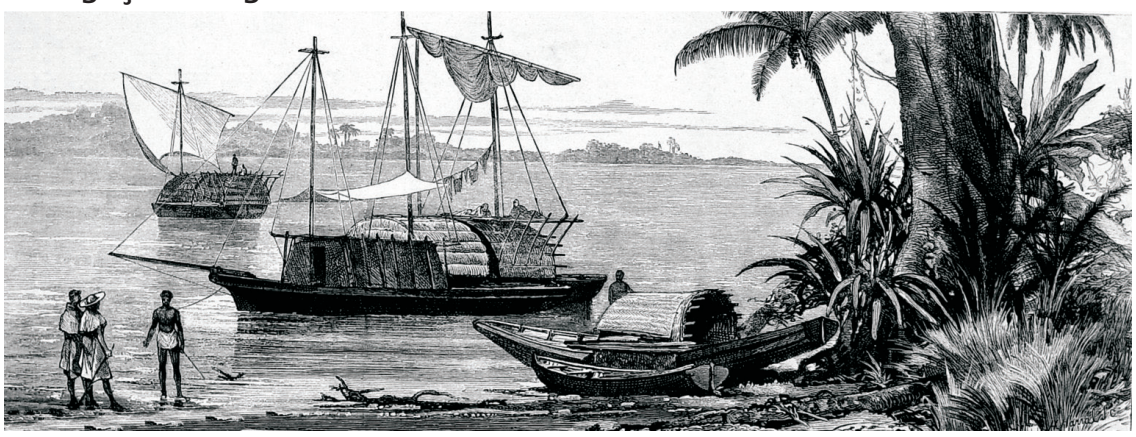

Fonte: Ilustração Brasileira, n.02, maio de 1877. Biblioteca Nacional

Tipos de embarcações no rio Amazonas

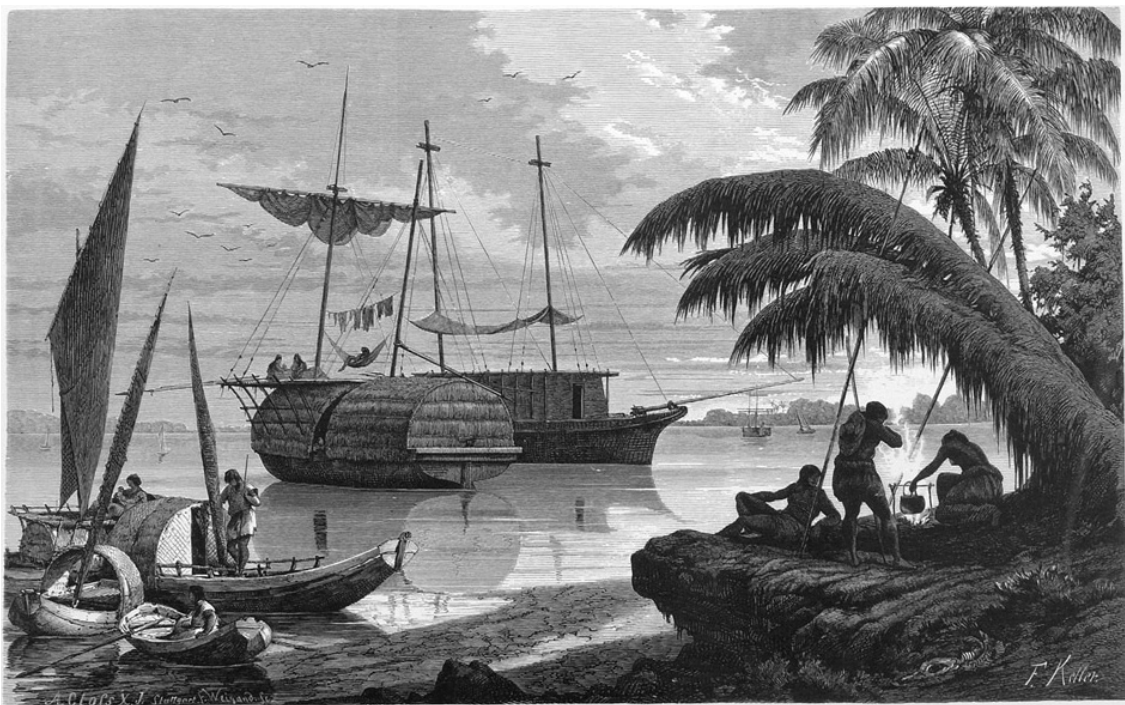

FAHRZEUGE VOM AMAZONAS UND RIO NEGRO.

$$
\text { Coberta, Batelio, Igarité und Montaria. }
$$

Fonte: Vom Amazonas und Madeira. Imagem enviada para a autora por Frank S. Kohl.

Esta composição de legendas e imagens opondo antigo e atual trazem informações novas, que não constavam na obra original. Em uma análise mais atenta, vê-se que ela era proveniente do mesmo ateliê de Sttugart, mas a assinatura era de W. E. A e não F. Keller, como estavam nas demais gravuras do livro.

Navegação atual no rio Amazonas

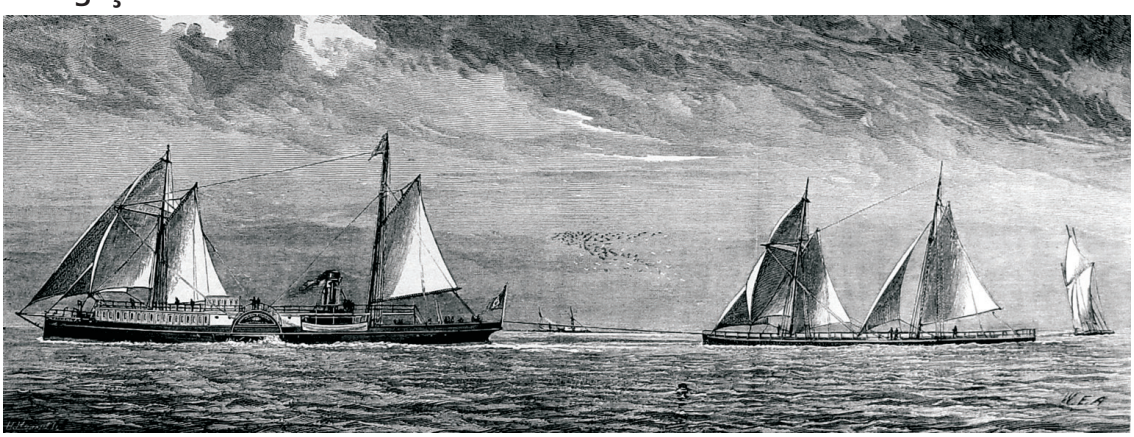

Fonte: Ilustração Brasileira, n.02, maio de 1877. Biblioteca Nacional.

Provavelmente, ao importar os clichês, esta imagem veio também e Fleiuss fez uma nova diagramação. Cabe comentar que na série de artigos publicados na Ilustração Brasileira, texto e imagem nem sempre estavam 
KELLER-LEUZINGER, Franz. Encontro com os Indios Caripunas. O Vulgarisador, n.1, p.10, 1877

54

Ibidem.

55

BELLUZZO, Ana Maria de Moraes. O Brasil dos Viajantes. Vol.2. São Paulo: Metalivros, 1994. p.138.

56

Ibidem. coadunados. No artigo que trazia as imagens das embarcações o texto era sobre a catequese dos índios e finalizava com a informação de que haveria uma continuação. No entanto, isto não ocorreu, ficando o leitor com uma visão bastante incompleta daquela viagem. A veiculação das imagens de Keller-Leuzinger nesta revista, entretanto, não terminaria aí. Encontramos vinhetas representando utensílios indígenas que adornavam as páginas do livro Vom Amazonas und Madeira e que foram utilizadas pelos editores da Ilustração Brasileira em 1878 em propagandas dos serviços do Imperial Instituto Artístico, sem referência a Keller-Leuzinger.

No jornal $O$ Vulgarisador, de Emilio Zaluar, que circulou no Rio de Janeiro entre os anos de 1877-1881, a primeira imagem da publicação representava o encontro de Franz Keller-Leuzinger com os índios Caripunas. 0 editor do jornal saudava a publicação em alemão afirmando que ela "deve interessar a todos que ligam a verdadeiro apreço aos trabalhos desta natureza, que, infelizmente, ainda tanto escasseiam entre nós"53. Neste jornal, o foco estava principalmente no encontro com os Caripunas, que são descritos da seguinte forma:

Eram criaturas fortes, bem conformadas e de estatura mediana; traziam pendentes comprimidos cabelos pretos; um dos homens apenas usava-os enrolados em trança. Um dente de anta atravessava-Ihes as pontas das orelhas, e tinha, além disto, em outro buraco na separação de nariz, um pequeno molho de penas encarnadas de tucano. Não traziam armas, a esta circunstancia junto à presença de uma de suas mulheres na embarcação, respondia-nos pela benevolência de suas intenções. ${ }^{54}$

Muito provavelmente em virtude do valor das gravuras do livro Vom Amazonas und Madeira e da ligação de Franz Keller com George Leuzinger, Franz Keller-Leuzinger é frequentemente lembrado na historiografia da iconografia no Brasil. 0 trabalho de Ana Maria Belluzzo em 0 Brasil dos Viajantes é exemplar neste sentido. Ela fora perspicaz ao analisar a passagem dos desenhos para a xilogravura. Para Belluzzo, este processo ressalta a imagem humana, que estaria apenas latente nos desenhos originais. "As poses clássicas das figuras e a concepção anatômica permitem harmonizar os movimentos interiores e correspondem às exigências de valorização do homem de acordo com a concepção neoclássica da época" ${ }^{55}$. Disto se depreende a força dos homens representados nos desenhos do engenheiro alemão, tornando um tanto contraditória a passagem que se segue fazendo-se necessário uma longa citação:

\footnotetext{
Os desenhos resultam do foco atirado sobre o sentido vital, introduzido pela natureza palpitante, da qual o artista acolhe o gigantismo para se comprazer na expressão sublime. Seu tema é a natureza indomada, à qual o homem se encontra sujeito. Keller-Leuzinger expõe a rivalizarão entre homem e natureza através do embate dos índios com os animais, da ação dos índios coletores, caçadores e tapires. Trata-se de concepção característica do que se convencionou chamar de romantismo europeu, que encontra na paisagem e no homem natural uma de suas expressões, concepções mais próximas da genealogia otimista de Rousseau. ${ }^{56}$
}

Nesta interpretação dos desenhos de Vom Amazonas und Madeira fica evidente que a autora praticamente se deteve neles, parecendo desconsiderar o texto. Para uma análise iconográfica eficaz é importante estar atento à dinâmica entre texto e imagem apontando que ora há uma relação complementar entre os dois registros e ora de contradição. Ao ler os relatos de Keller-Leuzinger fica difícil concordar com Belluzzo e a 
57

KELLER-LEUZINGER, Franz. Amazon and Madeira Rivers... Op. Cit., p.157.

58

Ibidem.
Cf. REIS, Arthur Cézar Ferreira. A Amazônia e a integridade do Brasil. Brasilia: Senado Federal, Conselho Editorial, 2001.

60

ANDERSON, Benedict. Comunidades imaginadas: reflexões sobre a origem e a difusão do nacionalismo. São Paulo: Companhia das Letras, 2008. influencia do bon sauvage de Rousseau na obra do engenheiro alemão. Ele, inclusive, afirmou em seu livro que estava "longe de se juntar à insustentável lamentação de romancistas sobre a iminente da mítica raça vermelha superior aos brancos em suas heroicas virtudes e nobres qualidades do espírito. Tal raça vermelha só existia na imaginação deles"57.

0 Amazonas para Keller-Leuzinger contava com uma série de desvantagens. Dentre elas, os indígenas que, segundo ele, eram "indolente, sensual e algumas vezes traiçoeira", mas estavam com os seus dias contados, pois deverão se entregar às "exigências da super populosa Europa"58. A solução para o Império, segundo ele, estaria na agricultura e na indústria, que deveriam suplantar o sistema extrativista sem um planejamento ordenado, que além de não promover o desenvolvimento desejado, colocava em perigo os recursos naturais que se esgotariam em poucas gerações.

Assim, ao analisar as formas de circulação da obra de Keller-Leuzinger pode-se verificar como a região do Amazonas e sua população eram representadas na imprensa nacional e internacional. A especificidade do relato deste viajante está na excelência de suas imagens que alcançaram grande circulação pela reprodutividade mecânica da imprensa de sua época, fazendo com que em alguns casos, a força da imagem suplantasse o texto.

\section{Conclusão}

A analogia do Vale do Amazonas como um "livro fechado" que precisava ser aberto principalmente por sábios e cientistas durou muito tempo e há atualmente uma intuição generalizada de que ainda existem capitulos a serem lidos. Apesar de a região ter sido visitada por vários viajantes desde o século XVI, como Pinzón, La Condamine, Agassiz, Martius, Barbosa Rodrigues, Wallace, Bates, Charles Hartt entre outros, permanece a impressão de "terra ignota". Isto pode ser atribuido a vários fatores, dentre eles, a resistência que o próprio objeto de estudo oferecia ao esforço de conhecimento. Cabe destacar que o termo "Amazônia" esconde uma diversidade geográfica, topográfica e econômica. Em outras palavras, como afirma Arthur Cézar Reis, a Amazônia não é uma só. ${ }^{59}$ Por isto não se pode generalizar a partir do relato de um só viajante. Por exemplo, as cachoeiras encontradas por Keller-Leuzinger não estão presentes em todos os afluentes da bacia amazônica e em grandes extensões o rio é facilmente navegável. A atenção para este ponto é fundamental para contestar a ideia da Amazônia como algo homogêneo que está longe da realidade.

Para uma apropriação efetiva e simbólica daquela área do território integrando-o como parte do restante do país, a imprensa, sem dúvida alguma, desempenhou um importante papel. Benedict Anderson já havia sinalizado as relações entre a circulação de impressos e a construção coletiva de um passado comum para a nação em seu livro Comunidades Imaginadas ${ }^{60}$. A partir dos avanços nas técnicas de impressão observadas na segunda metade do século XIX, as revistas e jornais, muitas vezes ilustrados, ganharam maior circulação. Um dos assuntos de grande interesse eram os relatos de viagem, que ao serem publicados nestes periódicos faziam com que os leitores "visitassem" locais distantes e até então desconhecidos e desenvolvessem um sentimento de pertencimento em relação a algo que nunca viram. 